\title{
A LEARNING OBJECT SUCCESS STORY
}

\author{
Robin Mason \\ Chris Pegler \\ Martin Weller \\ Institute of Educational Technology, \\ The Open University, UK
}

\begin{abstract}
This paper outlines an approach to designing a course entirely in learning objects. It provides a theoretical basis for the design and then presents evaluation data from a master's level course using this design. It also describes several re-uses of the learning objects on other courses and in different contexts. Each learning object is conceived as a whole learning experience, thus avoiding many of the problems associated with assembling components of disparate kinds.
\end{abstract}

\section{KEYWORDS}

Learning objects, holistic learning experience, re-usability, ePortfolio

\section{INTRODUCTION}

There is a whispering campaign to the effect that for all the hype about learning objects, all the resources devoted to developing appropriate standards, all the work on learning object repositories, nobody is actually using them in education and certainly nobody is actually re-using them.

What adds volume to the whispers about learning object feasibility is the lack of research into the pedagogical consequences of these systems and ways of thinking, and their epistemological and ideological implications [1]. This paper aims to counter this campaign with evidence from one example of both successful use and re-use of learning objects.

All of the activity and argument around the development and definition of learning objects has tended to obscure their essential purpose: that is, making opportunities for learning that are both effective and efficient. As is so often the case with new technologies, the hype surrounding them draws most of the attention, and little energy and research is devoted to serious study of their value in practice. One possible outcome of the whole focus on learning objects is not just reusable objects, but the development of shorter, independent and varied learning experiences These short learning events seem much more in tune with the demands of the workplace and of lifelong learning than traditional, lengthier course units.

The proponents of the learning object (LO) approach build their case on evidence of the following:

- Just-in-time learning (where you learn something at the time you need it) is much more effective than just-in-case learning (where you learn something without knowing if you will ever need it).

- Courses overloaded in terms of time and content lead to students dropping out. They also lead to surface rather than deep learning, as students do not have time to engage with the material.

- Campus students, 18-22-years-old, as well as adult professional learners are having to combine 
study with employment and to fit study time around a whole range of other activities.

- Attention spans are changing in response to hectic lifestyles, the impact of entertainment media and the overload of information.

- Only through learning objects can we support the sort of personalization and improved choice that learners now expect in their online experiences.

- Academics cannot produce resource material of sufficient quality, quantity and currency to meet rising student expectations unless they can reuse materials created by others or find more practical ways to re-purpose their own materials.

The detractors of the LO approach say it is a "dumbing-down" of the learning process and point to:

- The trivialization of knowledge, whereby ideas become reduced to a "soundbite."

- The lack of substance underlying the network of connections, so that one can go from one link to another without deriving any information of value or worth.

- The impossibility of atomizing learning, which occurs over a period of time and cannot be broken up into neat chunks.

- The breakdown of narrative flow that holds together the individual elements of a course or learning resource, leaving a series of disconnected pieces.

- The focus on content rather than discussion or dialogue in the learning process that is found in much of the learning object literature.

- $\quad$ Lack of evidence that learning objects have been or will be reused in practice.

Until there is greater use of learning objects in practice across a wide range of disciplines, and until there is more research on learning outcomes from programs developed in learning objects, there is a virtual standoff between these opposing views.

This case looks at reuse arising from a different and potentially more relevant approach, creating an online course wholly as learning objects (something few educators have yet attempted). We also explore the early reuse of these objects within the Open University (OU) across a variety of contexts and with migration between different platforms.

The rationale for re-using course material is that it should result in greater efficiency and higher quality learning opportunities for students. Not only can the most appropriate authors be used to originate the material, but the teacher is also freed up to concentrate on other teaching tasks by spending less time creating (and often replicating) the bulk of their learning resources from scratch. As noted by Downes:

The idea [of learning objects] is that you have a virtually instantaneous access to all possible learning and the way we do that is that we make it very easy to find learning and deliver learning. The way we make learning very easy to find is through the use of metadata. The way we make learning very easy to deliver is through our understanding of the pedagogy of learning objects. For example, we deliver in much smaller units of information than the typical class. We deliver five minutes of learning... Now that is the theory. It turns out to be a lot harder than people first thought. There are significant issues... [2]

Amongst these is the reality of searching for reusable material within publicly accessible repositories as experienced through the three cases at Athabasca University reported by Christiansen and Anderson:

The distributed model envisioned by Downes is not yet a reality. Issues relating to repository silos constrain the learning object economy and the free sharing of resources. The barriers to the 
learning object approach may also be cognitive barriers by faculty members in falling back into well trodden paths. The learning object approach is innovative and demanding to implement with search and retrieval issues being followed by a need for contextualization [3].

This reinforces what one of the earliest pioneers in the use of learning objects, David Wiley, has recently noted:

The commercial content industries have learned the hard way that, despite rights management attempts, digital content will make its way into free distribution. This fact of Internet life will prevent an 'educational object economy' in which large amounts of commercial content are available for purchase and reuse from ever materializing [4].

We will explore three issues:

- Course design using only learning objects

- The impact on student learning and study processes

- The re-usability of learning objects in practice.

\section{THE CASE STUDY}

The course which is the focus of this research is part of a Masters Program in Online and Distance Education offered by The Open University. The course is delivered at a distance based on online activity, and while it offers various forms of synchronous and asynchronous communication, there is no face-toface meeting. Now nearing the end of its second presentation, the course was first presented from March to October 2003 with 55 students, about half of whom were UK residents and the other half located all around the world. The evaluation referred to here is based on this first cohort.

The content of the course is constructed of 155 learning objects presented over four blocks, each block lasting for two months, and 'pre-versioned' to stand potentially as separate short courses in their own right. The course examines the impact of the internet and connectivity on learning from an individual, organizational, implementation and social perspective. It encompasses text, audio, animation, webcasts and audio conferencing activities to cover areas such as costing e-learning, organizational change, online communities and digital divide, as well as using new technologies such as instant messaging, collaborative tools and blogging. Each object is autonomous so that it can be re-used, removed or altered with relatively little consequence for the remaining objects. Each object is sufficiently rich and complex to achieve a specific learning outcome, but as learning objects the order of study and choice of objects studied can be varied by the student. One of the core principles of the course was that of choice-giving students opportunities to select which learning objects to complete, depending on their personal interests, job relevance or time and inclination. The course was deliberately designed to appeal to both the higher education and corporate sectors, through providing a wide range of substitutable topics and supporting several possible levels of engagement.

\section{A. Theoretical Underpinnings}

The instructional design principle underpinning this approach to learning objects centers on the notion of the integrity and autonomy of each object. Whereas some definitions might realize each element as an individual object e.g. readings, pieces of interactive multimedia, an activity, this approach implemented each object as a holistic learning experience with internal integrity. Wiley [5] suggests a continuum of objects from small, which are atomic such as single images, to large, which are aggregations of smaller 
objects, for example a web page with text, images and links. Our objects would tend towards the larger end of this continuum, which means they possess a high degree of internal context.

The integrity and autonomy of each object results in a level of learning object granularity somewhat larger than the norm associated with training materials or resources within repositories, though it is difficult to speak of a norm in an area as volatile and experimental as learning objects. What this approach does is place the notion of a learning object, and hence a course made from learning objects, into a holistic pedagogical framework where each learning object contains the essential components of an effective learning experience.

For example, our learning objects typically contain the major elements of a rich learning experience:

- A discursive element (the key issues and follow up readings).

- An interactive element (group or individual activity or online discussion).

- An experiential element (the activity).

- A reflective element (choice of readings and level of engagement).

Unlike content in a traditional course, where the explicit connections between concepts run throughout each unit, block, course, and increasingly within a program, each of our learning objects represents a miniature unit, complete within the bounds of the topic and ranging from 150-1500 words (usually with supporting conferences, audio, animation, online activity or printed/online texts) and typically 2-3 hours of student learning activity apiece.

\section{B. Research Methodology}

How well did this theoretical model work in practice? The impact on student learning and study processes was researched through the following four forms of data collection:

- Students were interviewed by telephone and their comments transcribed and compared.

- A web questionnaire was provided at the end of the course offering seven open-ended questions to gather student responses.

- Statistics comparing students' choice of learning objects for their portfolios were analyzed.

- The e-portfolios of student work submitted as the final piece of assessed work were read, doublemarked and analyzed.

\section{COURSE DESIGN WITH LEARNING OBJECTS}

While it is easy to see how teachers can incorporate learning objects into their course, whether it be lecture-based, print-based or online, it is somewhat more challenging to design a course entirely from learning objects. The reason is that teachers, whether in campus settings using lectures or in distance education using tailor-made print materials, are used to integrating instructions, objectives, and references forward and backward in the course material. In short, they view the course as one indivisible chunk (or in a modular course several indivisible chunks) which evolves with each successive presentation. Separating out these process elements from the content elements to reuse any content requires extricating references to other associated content, resources, instructions, activities, testing, and even personal comments and anecdotes from one interwoven, overlapping whole into separate stand-alone bits:

A common problem with conventional materials is that the instruction is inextricably linked with the resources, and it is very difficult to separate them out. When the various items are not 
designed and developed discretely, they can really only be used in the precise setting for which they have been built [6].

Introducing some learning objects into an otherwise traditional course does not disturb this integrated process, as the new material is essentially another resource on the course units. However, when the whole course consists entirely of discrete objects which do not refer to each other, where is the 'glue' that holds the course together and provides the value-added difference from self study or browsing in a library?

As learning objects are increasingly used to create whole educational offerings, the issue emerges of what constitutes the most useful level of granularity in practice. The solution described here was to view each learning object as a microcosm, somewhat akin to a lesson, or rather a distinct part of a lesson, dealing in a topic or a particular view of a topic. The learning object is conceived as a summation or expert overview of a topic that includes explanatory text, selected readings and follow up material, and activities in which the learner can engage experientially with the subject. Each object stands alone as a discrete learning opportunity, which the learner would ideally complete in one study session. The essence of the approach was to see the learning object as insulated or capsular in form but nonetheless a holistic experience for the learner: exposition, interaction, engagement, and feedback, all within a student-directed learning environment offering choice and flexibility for learners to investigate the topic in their own way. The "glue" is supplied in one non-reusable learning object at the beginning of each unit. Elsewhere we have described these glue objects as "narrative learning objects" [7]; each sets out the aims, highlights recurring themes, makes suggestions about how to tackle the work, and so on. By bringing together all the linking material into one place, the rest of the unit's learning objects can be internally but not externally integrated.

An approach to assessment was another integrating principle we used in the course design. The idea of an e-portfolio was in keeping with the learning object approach of the course: the construction of the portfolio resembled the construction of a repository of the outcomes of those learning objects that the student had chosen, supported by an integrative commentary, which acted as glue for their chosen objects. Students could work through a wide range of activities and submit a selection drawn from over 50 learning objects identified as suitable for assessment. Students were required to submit two activities from each of the four modules, making eight pieces of work in total. In addition, they wrote a 2000-word overview commenting on how their chosen activities supported their argument on the key statement:

Increased connectivity is bringing about a fundamental change in all aspects of learning.

At least two of the pieces of work had to come from collaborative activities, while the rest could be from the range of individual activities. The questions which arose from these design principles were:

- Would students' study processes be altered by the learning object approach?

- Would the e-portfolio prove to be the integrating element that was intended?

- Would the concept of learning objects as miniature learning experiences be effective?

\section{IMPACT ON STUDENT LEARNING AND STUDY PROCESSES}

While for us as course designers, the learning object concept was a significant departure from our normal practice, for most of our learners, there was much less impact. Typical comments during interviews were:

- I don’t think my study patterns were any different because of the learning object approach.

- I liked learning in small chunks and making a choice at the beginning of the week as to which learning objects to work on. 
- I really liked the structure and thinking behind the learning objects.

However, other students did comment on differences:

- I did notice a difference because a lot of courses I've studied, the materials were given in a more direct, less student-centered way. On this course, there was less material given and more that you did yourself.

- The separate learning objects did suit my own needs better, although they are not exactly coherent. I could jump from one to another and drop those I consider irrelevant to my objectives without being constrained by a linear plan.

- More disjointed and less of a community than on the other courses in the program.

The issue of choice-about which learning objects to tackle in depth, which readings to study and which completed activities to submit for the end of course portfolio-was a defining characteristic of the student-centered approach of the course. Close analysis of these choices reveals that the opportunity to "make your own course" was definitely realized. No two students submitted the same eight completed activities for assessment, and of the 55 learning objects permitted as evidence for the portfolio, students had chosen across the full range. In the interviews, we asked students to describe how they selected the objects, how many of the 155 objects on the course they completed, and how they worked on the activities. Their answers show a very wide variation in practice. Some students worked through all the objects, saying that they wanted to get a broad view of the subject; others read through all the objects and chose to work on those which were most relevant to their job. A few students admitted that they regretted not doing more of the learning objects, as almost without exception students were very positive about the content of the learning objects. Three quarters of the students were also very positive about the flexibility which the combination of choice and short discrete learning sessions provided.

"I had not encountered the LO approach to content before, but I found it instructive and stimulating. I felt that it offered me greater flexibility in how I approached my studies and what I studied," explained one student.

It was apparent from the interviews and other analysis that we had not used the glue object at the beginning of each week as well as we might. With feedback from the first cohort, we can now add much more advice about how to make choices and to work on the activities, and provide much more support in drawing out the overall themes and helping students get an overview of the course.

It was also apparent that our notion of completing a learning object in one study session was overoptimistic! On the whole, students spent considerably longer on each learning object than we had estimated. Essentially, we had developed enough learning material for two courses, not one!

One of the things we did seem to judge accurately the first time, was the balance between individual and collaborative work. It is well known amongst online teachers and learners, that collaborative work is very time-consuming and inflexible for busy, mobile learners. Furthermore, some students have a negative view of collaborative learning, though others find it essential to distance learning and to maintaining their morale. We provided on-going tutored groups and a range of synchronous technologies for those who really benefit from interaction. In each of the four modules we designed two fully collaborative activities (e.g. debates, role-plays) and a range of activities that might be termed "semi-collaborative." The aim with these partially collaborative activities was to build a sense of community, a sense of one's fellow students working on the same materials, a sense of sharing one's ideas and work, without being dependent on specific students to carry out their part of the work. So for example, one of these semi-collaborative 
activities involved writing a short piece to submit to the group and then drawing on other submissions to complete the activity; another involved keeping a blog as well as analyzing other students' blogs. In short, they were relatively time- and person-independent yet used the inputs of other learners. The balance we had chosen of individual work, semi-collaborative activities, and highly interactive collaboration seemed to offer opportunities for all types of learners.

\section{RE-USABILITY IN PRACTICE}

Within a remarkably short space of time (less than 12 months from the start of the original course) the learning objects within Learning in the Connected Economy have been reused within four new, separate contexts in the Open University. First, a short, ten-week course at the foundation level was created as part of a suite of short courses offered in the technology faculty. This new course comprised approximately 20 learning objects, only two of which were written specifically for it- $90 \%$ of the material being reused from the original master's course. Some very minor changes to the original learning objects were necessary given the changes in level and audience (UK teachers rather than global e-learning practitioners), however, the changes were minor, usually involving a reduction or alteration in external references, a different emphasis in scenarios and case studies, and occasionally an alteration to the type of activity. As well as re-versioned objects, a new final assessment, a course introduction and a weekly "narrative" object were created. This process took six weeks, including editing and publishing in a different online programme style on a completely different platform. This was significantly faster than the versioning work involved in generating other short courses in the series-all of which adopt a much faster production model than traditional OU courses, and averaged six months to produce. This short course, titled "Understanding eLearning: A Guide for Teachers and Learners," was launched in October 2003 and has three presentations (start dates) a year and currently recruits 100 students per presentation.

The second substantial reuse of the original learning objects was in the OU's Postgraduate Certificate in Teaching and Learning in Higher Education. Although an IET-based course, this differs substantially from Learning in the Connected Economy because it is a linear print-based course targeted at relatively new teachers in higher education, generally far less technically aware than students on the MA and predominantly teachers in conventional (offline) environments. In this case, the learning objects reused from the original course (25) served the purpose of providing additional content on elearning - two new sections within the course-and were also integrated with material that was versioned from print into digital learning objects to form a further updated section of the course. Two other parts of the course that had formerly been print-based were re-configured as digital learning objects to offer students more choice about the way in which they selected and engaged with the relevant content of these sections"Demonstrating' and 'Supervising." All of these re-used learning objects are delivered using a third style of platform, the OU’s eDesktop virtual learning environment.

Internal staff development has offered a fertile opportunity for further reuse of the original learning objects with staff across most faculties and departments of the OU. Nineteen of the original objects have been versioned, with minor rewriting, to suit an internal non-student audience, and are now offered to OU staff as three separate "series" (groupings) of learning objects under the "Hot Topics" brand. The three groupings (elearning, learning objects and connected learners) are described as issues-based CPD and use no new material and employ IET's Knowledge Network system to display materials online. The three groupings are supported by discussion and draw on the hundreds of online resources that populate the network - a key element in the OU's approach to gathering and disseminating knowledge about teaching and learning. The pilot series was launched in March 2004 and has been heavily over-subscribed (70 staff yielding over 134 series registrations). Feedback at the half-way stage (three weeks into the first series) indicates that over $90 \%$ of the first cohort would enroll in a future Hot Topics series if the subject 
interested them-the remainder preferring a face-to-face scheduled workshop.

To adapt the learning objects to support staff development it has been necessary to provide simple advice on how to approach the learning object so that study can be completed within the two hours per week suggested as a guide. This was done by offering a separate "study strategy" section to advise users on the options. As with the students studying learning objects in the original master's course, some of the Hot Topics subscribers would like more time to complete the activities in depth, but the potentially flexible approach to sequencing is valued for the same strategic reasons given by the master's students. Staff were able to adapt the learning objects to their own needs. As one said, "Not starting from sea level, I have been able to read things quite quickly and identify what's new.”

Further reuse of individual subjects continues to occur, and as awareness of these objects has grown, others within the OU are using individual learning objects in new, sometimes non-course, contexts. Examples include use of one object that looks at coping with information overload, as the seed for a miniseries of learning objects for a regional training programme on time management. Others have been used by the library as part of a briefing on metadata, one on learning objects used to inform discussion amongst researchers and others (from H850) by a student working on an LTSN project. We anticipate further use and reuse of learning objects within the OU to generate a new series of Hot Topics and are investigating their potential as an updating resource for our MA alumni.

While reusing objects has in each case required some small revisions or adaptations, this has accounted for, in each case, only a fraction (estimated as less than 5\%) of the time that it took to write the original learning objects. We could reasonably anticipate further reuse of the original material, particularly the reuse which we pre-versioned it for - the use of each module as a stand-alone short course. Overall, the project realized a very considerable saving in costs and, particularly in terms of staff development, created opportunities that would not otherwise have existed.

\section{SUMMARY}

We have outlined a theoretical model as well as a practical implementation of one approach to the use of learning objects. The objects are re-usable because they are small, stand-alone and yet with total internal coherence. Because they contain all of the important components of a deep learning experience, they are engaging and well liked by students. The model has been demonstrated to be adaptable at undergraduate as well as graduate level, for fee-paying students as well as for internal staff development, and has been applied across four different platforms and with a variety of supporting technologies.

The use of an e-portfolio as a final assessment provided a strong integrating factor on the original course, giving students an opportunity to draw together the various themes and modes of delivery. Whatever the assessment method, it should provide this function, but it is especially necessary on a course developed entirely in learning objects.

It is interesting to us that this holistic approach to learning objects is a solution that others are also beginning to discover as a way of overcoming, at least partially, some of the bittiness associated with the concept of a course of learning objects. This approach is yet to be explored in independent or commercial re-use. What made our approach so successful was that we developed all the content from scratch, and although our objects were by no means all similar, and we did commission some objects from consultants, they clearly all worked together and have continued to work in new combinations and contexts. Our re-use of these learning objects is within the same organization (the OU), and so far, led by 
the original authors. There is now considerable interest in working more widely with learning objects in many parts of the OU. We feel we have demonstrated a viable and highly successful approach to the use and re-use of learning objects.

\section{REFERENCES}

1. Friesen, N. Three Objections to Learning Objects. In Online Education Using Learning Objects, ed R. McGreal. Taylor \& Francis Books Ltd, London: 2003.

2. Downes, S. Interview with Stephen Downes. In The Future of e-Learning: Realities, Myths, Challenges and Opportunities. North Roundtable on e-Learning, 2003: 164-5. Online: http://www.cnorth.edu.on.ca/cnorth/e-Learning/e-LearningInterview.pdf.

3. Christiansen, J. A. and T. Anderson. Feasibility of Course Development Based on Learning Objects: Research Analysis of Three Case Studies. International Journal of Instructional Technology and Distance Learning: March 2004. Online: http://www.itdl.org/Journal/Mar_04/article02.htm.

4. Wiley, D. Learning Objects: Difficulties and Opportunities. David Wiley’s Stuff, 2003. Online: http://wiley.ed.usu.edu/docs/lo_do.pdf.

5. Wiley, D. Getting Axiomatic About Learning Objects. The Instructional Use of Learning Objects, 2003. Online: http://reusability.org/axiomatic.pdf.

6. Oliver, R and C. McLoughlin. Pedagogical Designs for Scalable and Sustainable Online Learning. In Reusing Online Resources: A Sustainable Approach to eLearning, 100. Kogan Page, London: 2003.

7. Weller, M. J., C. A. Pegler, and R. D. Mason. Working with Learning Objects-Some pedagogical Suggestions, 342-349. ALT-C, Sheffield University, September 2003.

\section{ABOUT THE AUTHORS}

Professor Robin Mason led the team which developed the Learning in the Connected Economy course. Dr. Martin Weller wrote the majority of the learning objects and made the first re-use on an undergraduate course. Chris Pegler authored a third of the learning objects and carried out the other reuses. All three authors are academics in the Institute of Educational Technology, The Open University. 
